\title{
O nacional e o estrangeiro em Marco Zero, de Oswald de Andrade
}

\author{
Wagner Fredmar Guimarães Júnior* \\ Universidade Federal de Minas Gerais \\ Belo Horizonte, Brasil \\ Recebido em: 30/04/2019 \\ Aceito em: 30/05/2019
}

Resumo: O presente artigo analisa o romance Marco Zero, de Oswald de Andrade, sob uma perspectiva materialista, a fim de demonstrar como se dá a correlação entre o nacional e o estrangeiro na composição da obra. Estruturado através da articulação entre a forma mural mexicana, composta de fragmentos, e o narrador pedagógico, Marco Zero comunica sua visão crítica acerca dos eventos históricos figurados. Assim, o autor paulistano se vale das formas estrangeiras, empenhando-as para a representação crítica da realidade brasileira dos anos 30.

Palavras-chave: Marco Zero. Oswald de Andrade. Forma literária e processo social.

\begin{abstract}
This article analyses Oswald de Andrade's novel Marco Zero, from a materialist perspective, in order to demonstrate the correlation between the national and the foreign in its composition. Structured by the articulation between the Mexican mural form, made of fragments, and the pedagogical narrator, Marco Zero expresses its critical view about the historical events represented. Thus, the Paulistan author uses foreign forms in order to critically represent Brazilian reality of the zo's.

Keywords: Marco Zero. Oswald de Andrade. Literary form and social process.

Resumen: El presente artículo analiza la novela Marco Zero, de Oswald de Andrade, desde una perspectiva materialista, a fin de demostrar cómo se da la correlación entre lo nacional y el extranjero en la composición de la obra. Estructurado a través de la articulación entre la forma mural mexicana, compuesta de fragmentos, y el narrador pedagógico, Marco Zero comunica su visión crítica acerca de los acontecimientos históricos figurados. Así, el autor paulistano se vale de las formas extranjeras, empeñándolas para la representación crítica de la realidad brasileña de los años 30.

Palabras-clave: Marco Zero. Oswald de Andrade. Forma literaria y proceso social.
\end{abstract}




\section{Introdução}

No clássico ensaio "A carroça, o bonde e o poeta modernista”, Roberto Schwarz propõe uma leitura materialista da poesia de Oswald de Andrade, buscando demonstrar que o escritor não se reduz ao seu "conhecido perfil do modernista de primeira linha, subversor exímio de linguagens, crítico e revolucionário nesta medida" (SCHWARZ, 1987, p. 14). Essa visão, bastante difundida na crítica oswaldiana até os dias de hoje, ao focalizar isoladamente a dimensão da inventividade linguística/artística, que é, sem dúvida, um aspecto essencial de sua obra, acaba deixando de lado a matéria histórica, dimensão complementar e indissociável. Assim, o crítico propõe que a elaboração formal seja analisada em função da matéria que organiza, de modo historicamente mais especificado. Dito de outro modo: o trabalho formal realizado por Oswald deve ser analisado em função da matéria brasileira, lido à luz da relação dialética entre forma literária e processo social. Pensar a obra oswaldiana da forma como fazem Haroldo de Campos (1957) e Décio Pignatari (1964) - para ficar apenas nos críticos de maior envergadura - é, sem dúvida, de grande relevância, no entanto, reforça a imagem de que o veio crítico de Oswald se restringe a realizar procedimentos estéticos e experimentações linguísticas, daí o espanto de grande parte da crítica quando do lançamento de Marco Zero, em 1943 e 1945. O que foi visto como uma mudança total de rumo na obra do escritor, que antes disso não seria crítica ao processo histórico brasileiro, sendo crítica apenas pelo trabalho formal tomado como algo distinto e separável dessa primeira dimensão, é um desdobramento de um processo de tomada de consciência que já vinha sendo gestado em sua obra poética e de ficção e estoura após a quebra da Bolsa, em 1929, culminando em sua entrada para o PCB e na sua militância política.

Consideramos que uma leitura integradora dialética, que busque pensar criticamente as relações entre forma literária e processo social configuradas nas obras, seja mais produtiva e penetre com mais profundidade nelas. Entendo que um Oswald como o que Roberto Schwarz busca afastar, um "subversor exímio de linguagens, crítico e revolucionário nesta medida" (SCHWARZ, 1987, p. 14), não 
sobrevive a uma análise das obras elas mesmas, uma leitura criticamente armada à luz da realidade brasileira. Assim, tendo em mente uma concepção de vanguarda não restrita ao estético, que entenda o termo como "inovações artísticas de antagonismo radical face à ordem estabelecida no domínio artístico (forma e temas) e no plano geral (político social)" (BOAVENTURA, 1985, p. 20) articuladamente, demonstrarei como Marco Zero resulta da utilização de procedimentos técnicos e concepções históricas e políticas de vanguarda, empenhados para a representação crítica da realidade brasileira, como parte que é do concerto das nações. Em suma, demonstrarei a partir de dois aspectos principais (Muralismo Mexicano e o narrador crítico) como o problema do nacional e do estrangeiro se formaliza em Marco Zero.

Em 1933, Oswald de Andrade anuncia o projeto de Marco Zero e inicia sua redação. Estavam previstos cinco volumes. Além dos dois publicados, A revolução melancólica (1943) e Chão (1945), seriam escritos Beco do escarro, Os caminhos de Hollywood e A presença do mar:

\begin{abstract}
Nos dois primeiros, exporia suas teses sobre o levante paulista de 1932, a permanência do latifúndio no contexto de modernização do país e a emergência do proletariado como força revolucionária. Nos demais trataria dos novos mitos e ideologias que se difundiam em São Paulo, importados do capitalismo norte-americano (FERREIRA, 1996, p. 25).
\end{abstract}

Desde 1935, Oswald divulgava fragmentos do trabalho em diversos periódicos, além de realizar leituras de trechos em sua casa, em que estavam presentes convidados como Antonio Candido e Gilda de Mello e Souza.

Para a realização do romance, sem abrir mão das conquistas de técnicas e procedimentos artísticos do Modernismo, Oswald se apoia nas vanguardas de orientação socialista, que articulavam pesquisas estéticas e concepções ideológicas revolucionárias e davam um sentido social, político e prático à arte, entendida como instrumento para a construção do futuro e aprimoramento da consciência. Foram muitas as influências do escritor paulistano, vindas das artes plásticas, do 
cinema e da literatura propriamente dita: Muralismo Mexicano, Eisenstein, nomes do Máximo Górki, Mikhail Cholokhov e Feodor Gladkov, dentre outros. Verificase, ainda, a relação de Oswald com o Cubo-futurismo russo. Sábato Magaldi (2004) fala da influência da peça $O$ mistério bufo, de Maiakovski, no teatro de Oswald, formalizada no procedimento de representação de um grande painel histórico e político que condena o mundo antigo em função de um homem novo, nascido do proletariado triunfante. Pode-se identificar na configuração de Marco Zero a mesma estrutura, a ideia do teatro de tese, além da própria ideia cubo-futurista do poeta como tamboreiro da revolução, segundo a qual o artista é um artistamilitante. Devido ao estágio em que esta pesquisa se encontra, nosso foco aqui se restringirá ao Muralismo Mexicano e à figura do narrador do romance.

Marco Zero é concebido sob inspiração principalmente do Muralismo Mexicano. Oswald foi influenciado pelos principais nomes desse movimento: David Alfaro Siqueiros, Diego Rivera e José Clemente Orozco. A ideia do mural mexicano, um painel social, servia muito bem ao projeto do escritor paulistano de representar as contradições do processo histórico brasileiro da década de 1930. O afresco social, forma artística da pintura muralista, preside todo o romance, que é construído pela utilização de procedimentos técnicos como fragmentação, simultaneidade, montagem, elipse, corte de cenas e caracterização concisa. Caracterizado a partir do estado de São Paulo, Marco Zero abrange dos momentos que antecedem a Revolução Constitucionalista de 1932 até o ano de 1934, na Batalha da Praça da Sé, constituindo um verdadeiro mural social do período. Esse painel retrata, do rural ao urbano, a ação simultânea de vários grupos sociais, desde posseiros pobres e espoliados, migrantes e imigrantes, proletários e comunistas, até a burguesia paulista e a velha aristocracia decadente.

Vendo as coisas de uma perspectiva comparatista materialista, sem a ideia esteticista de vanguarda, a influência do Muralismo ${ }^{1}$ em Marco Zero vai muito além dos procedimentos artísticos propriamente ditos, entendidos meramente como linguagem artística. As técnicas e procedimentos artísticos importados carregam consigo as concepções ideológicas progressistas e o contexto social de onde foram

\footnotetext{
${ }^{1}$ Sobre o Muralismo mexicano, ver o excelente trabalho de Rita Eder (1990).
} 
trazidas, que são repensados para o contexto brasileiro, passando por uma filtragem reordenadora ${ }^{2}$ que as torna nacionais. Assim, a forma artística que surge em Marco Zero resulta da junção crítica da forma artística mexicana (técnica artística + realidade social) com a realidade social brasileira, além dos demais procedimentos utilizados, das influências nacionais do Romance de 30 e de vanguardas como o Futurismo e o Cubismo. Guardadas as devidas proporções relativas às diferenças dos processos históricos dos dois países (Brasil e México), note-se que as "familiaridades" existentes nessa comparação são explicadas por se tratarem de duas nações periféricas, onde o problema do nacional e do estrangeiro possui um caráter geral de semelhança.

Nesse sentido, as concepções ideológicas do Muralismo, baseadas na realidade daquele país, se transformam em forma artística, que por sua vez ganha nova função ao ser utilizada para representar outra realidade social, a brasileira. Tendo isso em mente, procuramos demonstrar como a forma mural, transformada em romance, juntamente com um tipo específico de narrador, são empenhados criticamente por Oswald para representar a realidade brasileira. Isto é, como o trabalho formal de Marco Zero, nesses aspectos bastante pontuais, trata de organizar a matéria histórica brasileira para produzir sobre ela uma interpretação crítica.

A forma mural atende ao anseio de Oswald por representar o painel social que pretendia, incluindo em Marco Zero as várias classes que compunham o quadro social da década de 30 , e as figurando na posição ocupada naquela sociedade. Para uma leitura crítica da história do Brasil, a partir do estado de São Paulo, o autor coloca juntos: explorados e exploradores; negros, índios e nordestinos; a aristocracia decadente e a burguesia nascente. Essa coexistência das classes no espaço do romance mural, em luta, revela ao leitor como as desigualdades sociais são produzidas, historicizando-as e apontando, mais ou menos diretamente, para a perspectiva de uma mudança social necessária. Essa totalidade é composta por diversos fragmentos e flashes que vão trazendo, como

\footnotetext{
${ }^{2}$ Termo utilizado por Roberto Schwarz (2014, p. 28) para descrever o processo de aclimatação das formas artísticas europeias ao contexto local. Ressalte-se que o mesmo raciocínio pode ser empregado para a reflexão sobre a aclimatação do Muralismo no Brasil.
} 
num processo de montagem, a sociedade brasileira para o romance. Como a ideia é que a coletividade seja o grande personagem, a psicologia dos personagens não se aprofunda, para o que servem muito bem as pequenas cenas de que o livro é majoritariamente composto. A forma mural seria, ainda, uma mimetização da realidade, que apenas em aparência é algo fragmentado e desconexo.

Essa forma se efetiva em Marco Zero com o dispositivo do narrador crítico/pedagógico:

A escrita fragmentada, simultaneísta e de montagem [...] era mais uma vez o recurso para acomodar sentimentos, ideias e imagens. Ela recebia agora uma disposição pedagógica, inspirando-se tanto nas artes plásticas quanto na cinematografia da vanguarda socialista (FERREIRA, 1996, p. 24).

Para essa construção, Oswald recorre a uma forma dramática, utilizada, entre nós, no romance por Machado de Assis. ${ }^{3}$ Sem afirmar que se trata de uma simples transposição da forma dramática ou do narrador machadiano, pode-se dizer que existem semelhanças entre esse procedimento e o narrador oswaldiano de Marco Zero, que não se resume a isso e também age de outras formas no livro. O narrador de Oswald cumpre o papel de organizar os fragmentos apresentados, dando-lhes uma lógica e estabelecendo a conexão de significados entre as partes dispersas. Opera também, em determinadas situações, oferecendo sua avaliação crítica acerca da matéria narrada, a fim de que o leitor tome consciência das contradições apresentadas pelas ações dos personagens em seus diálogos. Ele descreve os fatos, entra na consciência dos personagens, faz avaliações acerca de suas posturas e do modo como agem. Esse movimento do narrador de se distanciar dos eventos apresentados pelos fragmentos e comentar criticamente a matéria narrada corresponderia, guardadas as possíveis diferenças, ao movimento da parábase - o que será investigado posteriormente. Fato é que o narrador estimula o leitor a ser crítico, posicionando-se diante do que é dramatizado. Em Marco Zero, o narrador funciona como a consciência histórica e crítica do romance, sendo a instância máxima de opinião do livro, essencial para a difusão das visões de mundo de Oswald e do Partido Comunista. Ele acaba potencializando as cenas antes

\footnotetext{
${ }^{3}$ Sobre isso, ver o excelente livro de Souza (2006).
} 
apresentadas ou muitas vezes fazendo a crítica diretamente, ao falar do interior da consciência dos personagens. Partindo do que foi brevemente apresentado sobre a forma mural e o narrador, vejamos alguns trechos do romance em que isso ocorre.

Na passagem seguinte, o narrador introduz brevemente o fragmento, que é seguido pelo diálogo entre os trabalhadores e os membros do Partido Comunista, e vai dando andamento à cena por meio de pequenos comentários. No diálogo, o campesinato mostra-se consciente acerca da necessidade do comunismo como saída para o Brasil, inclusive para o problema da grilagem de terras, que no livro é realizada pelo Major Dinamérico Klag, dono do latifúndio da fazenda Formosa:

O dia de trabalho havia terminado na mata, Os trabalhadores recolhiam para o rancho, onde o Mingo preparava o jantar.

- Ah! se fosse verdade o espiritismo!

- Por quê?

- Pra gente vortá traveis moça. Diz que contece mas a gente non sabe quin foi antes. Intó de que serve?

O camarada Rioja tratava de encaminhar a velha para as realidades do presente.

- Seria bom que viesse pra cá o comunismo. Cabava os capitalista, nóis non brigava mais por causa da posse da terra. Ficou pensativa no banco longo e estreito do rancho.

- Io só fiz uma bestera de boa-fé. Trocá uns sobradinho da Rua dos Instudante co estas terra que o Majó diz que é dele mas non él Desque mataro o Pedrão na estrada eu bandonei o bananá. [...]

Houve um silêncio de mato.

- Mas estas terra que eu trabaio e que passei iscritura não pode caí nas unha do Majó. São gente da Formosa. Um fazendão. Não chega? Inda qué pigá as terra dos pobre. Se o comunismo não vem logo, eu mato um. Pronto! Vô na cadeia!

No silêncio vegetal, corria a água de um riacho. A velha fitava o chão, a cabeça enterrada no chapéu. Exclamou de repente:

- Manda preguntá lá na Rússia quando é que vem o comunismo!

Leonardo deu uma risada clara.

- Eu tenho pressa. Estô ficando na merda. Banana! Meu dinheiro foi suado, fio da puta! Io fiz a permuta de boa-fé, no tabelió. Agora eles vem dizê que era do santo. Santo non precisa de terra, já tem o céu! [...].

Os trabalhadores quietos esvaziavam os pratos enormes em garfadas regulares e iguais. A Miguelona tirou de novo o caldeirão do fogo para servir. (ANDRADE, 1974, p. 28-31). 
Após o fragmento, há o comentário do narrador, uma mistura da sua avaliação sobre a conjuntura do país com a leitura do personagem comunista Leonardo Mesa. A observação feita defende que a saída para a situação do campesinato seria a radicalização rumo à futura e verdadeira revolução, em tudo diferente da modernização conservadora trazida pela "Revolução" de 30 :

\begin{abstract}
Os camponeses tinham uma idéia assombrada de tudo. Quem não tinha no Brasil da Revolução de zo? Ò que importava, pensava Leonardo, era prepará-los para o futuro, dirigi-los nas convulsões que se anunciavam, radicalizá-los na crise. O camarada Rioja queria constituir uma célula comunista na mata. Provocou para isso uma reunião dos trabalhadores no rancho de baixo, onde havia plantações abandonadas. Renques de bananeiras ofertavam seus cachos inúteis. Um abacaxizal enorme abriase em frutos e farpas. (ANDRADE, 1974, p. 31).
\end{abstract}

As passagens seguintes são as últimas de $A$ revolução melancólica, primeiro volume de Marco Zero. Após a tentativa de golpe contra o governo de Getúlio Vargas, evento conhecido como Revolução de 32, em que os paulistas são derrotados pelas tropas federais, tudo volta ao normal e ocorre uma romaria na cidade interiorana e pobre de Jurema. O militante Leonardo Mesa tem seus planos de propaganda comunista frustrados pelo evento religioso. Aqui, a função desempenhada pelo narrador é a de fazer uma espécie de balanço dos eventos figurados no livro e, consequentemente, da conjuntura política do Brasil e do mundo, criticando o papel da religião como alienação. Se num primeiro momento ele está na consciência do personagem Leonardo, posteriormente ele tece suas próprias avaliações:

Leonardo Mesa pensava que a festa de Jurema atrapalhara todos os seus planos de propaganda. Pagou o café, rasgou em pedacinhos a carta que trazia do líder Piratininga, para em nome do Rebouças Clube abordar o médico instalado em Bartira que era negro também. Iria à Formosa ver Jango. [...]

Hoje, mitos novos e vitoriosos fluíam da vida política. O irracional desembocado sem pelas das malhas individualistas do capitalismo. $\mathrm{O}$ fascismo! O troglodita debatendo-se num último alento às portas da socialização. $O$ ressentimento que a igreja causara afastando-se do mundo vivo não havia chegado ao Brasil. Era ainda o Cristo pobre e milagreiro da Galiléia para quem afluíam os caminhões dos romeiros, desconsolados pela vida árdua. Como negar sentido a essas concentrações onde homens e mulheres iam buscar o apoio que lhes não dava a existência cotidiana? Religar, unir. Reunir. Uma nova religião 
abria-se para o mundo, saía das catacumbas para o tumulto da Ágora e com certeza para os morticínios de amanhã.

Os caipiras haviam se levantado.

- O saci não existe.

- Esse eu vi.

A jardineira parou. Leonardo tomou o último lugar.

(ANDRADE, 1974, p. 277-278).

Na continuação do fragmento, o narrador entra novamente na consciência do personagem e, de lá, realiza avaliações sobre a situação nacional, propondo pautas como a reforma agrária, a desmistificação da religião e criticando a Revolução de 32, desvendando o caráter de classe do evento histórico. A ideia de que o Brasil deveria se industrializar e abandonar a posição agrária e submissa no contexto do capitalismo mundial é central para todo o livro. O trecho termina poeticamente com versos de Lorca, como que anunciando um futuro melhor para o país, que viria, segundo ele, com a revolução proletária, no campo e na cidade:

O marxista imaginava as transformações que o Brasil ia sofrer com a queda ao latifúndio e o esfacelamento da monocultura. A mística daquela massa compacta, que assistia anualmente à festa do Bom Jesus de Jurema, sofreria com a derrocada.

Já com a revolução do ano anterior, 32, anêmico revide do fazendeiro instalado secularmente no planalto - o paulista mudara. Tinha saído de casa. O caminho era o entrosamento anunciado no ritmo que a história humana impunha. O Brasil... As proximidades econômicas do latifúndio, as proximidades étnicas do negro, do índio e do europeu medieval, tudo isso iria no roldão de um dia novo. De um dia industrial.

A jardineira batia a estrada larga, subindo, descendo, por entre semeaduras e paisagens. Os versos de Lorca continuaram a lhe vir à boca: Que se cumpla lá voluntad de la tierra

Que da sus frutos para todo

(ANDRADE, 1974, p. 277-279, grifos do autor).

Aqui, Dinamérico Klag Formoso está no banco Abramonte para tentar resolver a sua dívida e salvar a fazenda da família. O narrador, antecipadamente ao fragmento em que Dinamérico conversa com o gerente do banco, historiciza a situação e explica ao leitor o que está ocorrendo, dando unidade à forma fragmentária dos diálogos e atuando na construção do significado do acontecimento no romance:

Dinamérico Klag estava só diante da secretária fechada de Mauro Tolosa que tardava em chegar. Frente a ele a janela do escritório Spin, no edifício Arquipa, aberta sobre os arranha-céus. Restava-lhe dar um tiro no 
ouvido. Era como tinha que acabar. Naquele momento todas as fúrias do inferno vinham flagelá-lo. Não era remorso algum. Mas as circunstâncias acuavam-no como oficiais de justiça, intimidativos e presentes. Procurava ainda persuadir-se de que havia saída. A Santa do Brejal enviaria o "guia" para ditar-lhe as soluções. Uma voz gritou-lhe ao ouvido: - Por que você não se atira dessa janela abaixo? São dez andares. A calçada espera o seu crânio. . .

Estava inteiramente batido, agarrava-se solidamente às bordas do móvel de aço. Fora sempre um criminoso fracassado. Levantou-se. Viu-se ao espelho do porta-chapéus, os olhos vermelhos, a cara velha, os dentes podres. Era o filho de um senhor arruinado. Que estudara altas coisas numa outra era, numa era de prosperidade. A crise o fizera regredir. Tivera que recuperar a terra à rebenque e a tiro como seus ancestrais na Formosa. Tudo se firmaria se não fosse a derrota de 32. E fora traído por seu próprio filho.

Lá fora os carros buzinavam no movimento urbano. Foi olhar-se de novo ao espelho. Abramonte ameaçava-o. Os cheques sem fundo seriam inexoravelmente protestados. E as letras depois. Não havia recursos para salvá-los. Os parentes tirariam o corpo. Ele iria, depois de um processo escandaloso, mofar na Penitenciária! Vitalino avisara-o que ele seria denunciado por Abramonte. E o advogado não vinha. Spin na sua sala faustosa nem sequer o receberia. Era Tolosa quem teria de resolver, procurar uma saída. Ele não poderia evitar que o prendessem. Se fugisse para a serra, fosse morar lá com Quindim e a Ciana, iriam buscá-lo com escolta à qual se juntariam os posseiros da Miguelona. . . Além de arruinado ia ser preso... Deu uma risada. Era mais que trágica a sua impotência... Era humorística! Ele já sentia que todos gozavam a sua derrota. Até Eufrásia... No entanto era um benemérito, pretendia espalhar a riqueza de seu espírito pela terra... Se Eufrásia se aquietasse a seu lado escreveria um livro maior que a Bíblia.

A cidade entrava pela janela em múltiplos barulhos. São Paulo erguera cubos enormes atestando a vitalidade da comunidade ativa da cidade. Ele fora eliminado de todo progresso da urbe. Agora o descalabro final vinha de um baque. . . Aqueles sórdidos que dominavam o Triângulo não tinham raça, não tinham pedigrees, vinham das senzalas, dos chiqueiros das colônias, dos ergástulos de seus avós. Amea- çavam-no. Porque eram os donos vis do dinheiro. O seu fundo medieval recusava-se a compreender, a aceitar a transformação utilitária do mundo e a quebra dos seus valores eternos. Era uma subversão. E tinham como exatores gente paulista a seu serviço. Tomou rapidamente o telefone. Iria despejar sobre Vitalino a sua fúria de quatrocentos anos. Salafrário! Trair assim a gente paulista!

Diante da voz do gerente o Major teve uma risada sarcástica. Disse quem era. Esperaria a primeira ameaça para desabar sobre ele. Sentia a cólera de um Deus. (ANDRADE, 1978, p. 106-107)

O narrador entra na consciência de Dinamérico para, de lá, narrar. Através desse procedimento, o leitor toma conhecimento da origem das terras do latifundiário decadente, fruto inclusive de grilagem e roubo. Toda a atmosfera da decadência narrada é contraposta pela terceira parte do trecho citado, que pelo seu início ("Lá fora os carros buzinavam no movimento urbano") anuncia os novos tempos, aludindo ao fato de que o latifúndio está em decadência e em vias de 
desaparecer. A narração da decadência continua. $O$ fragmento seguinte anuncia, mais uma vez, os novos tempos em que o progresso, a cidade, engoliriam o campo e o atraso do latifúndio. Evidenciam, ainda, o sentimento da aristocracia decadente em relação à mudança que a modernização traz no país; tudo isso é visto como “uma subversão”. Após o esforço prévio do narrador, vem o fragmento:

- Como vai essa bagunça aí?

- Vamos indo.. . Por que você não aparece?

A voz de Vitalino era doce e calma, o contrário do que ele esperava para reagir.

Você está na cidade, Major?

-Estou! -

Eu preciso falar urgentemente com você...

- Sei...

Você preparou uma cilada..

— Não! Dou a minha palavra! Venha cá! Pode ser que

eu arranje tudo.. . Mas venha já . . . Venha! Eu me responsabilizo. . . (ANDRADE, 1978, p.107).

Com a leitura do fragmento acima, completa-se o caráter crítico da situação. O leitor, já munido das informações trazidas pelo narrador, possui elementos para extrair daí a visão crítica comunicada pela obra acerca da decadência do latifundiário.

Nessa passagem, o procedimento do narrador é o mesmo. Elucidando questões apresentadas em fragmentos anteriores, o narrador entra na consciência do personagem comunista Leonardo Mesa, que acabara de ser preso, e de lá faz sua avaliação da conjuntura do país. As visões de Leonardo e do narrador se confundem e, nesse trecho, o procedimento acaba funcionando como uma forma de o narrador revelar certos posicionamentos políticos e conjunturais. Fica explícito que, para ambos, a solução para a exploração do trabalhador (no campo e na cidade) seria a reforma agrária, que manteria no campo o campesinato, freando o processo de proletarização a que estavam submetidos na zona urbana:

A lâmpada do alto batia no rosto de Leonardo. Parecia-Ihe que não estava mais preso, que estava num trem. Quando viria a tomada do poder? Ele via em sonho o êxodo do campo. No momento, a atração que exercia a cidade não passava de uma mudança do modo de produção que a humanidade usava para subsistir e progredir dentro de suas condições históricas. Era a força revolucionária da máquina que chegava àquele canto perdido do mundo - o Brasil. A gente arruinada da província 
procurava a cidade. Eram os Frelin, vindos de Brejal, era a pequena Felícia recitando versículos da Bíblia. Um passarinho alegre a manso. A fábrica constituía um signo de civilidade. Os rapazes e as moças não pensavam na escravidão que trazia a condição de operário. Só enxergavam as vantagens exteriores da cidade. O vestido de seda vistoso, o sapato lustrado. Uma meia fina, um cabelo em permanente. Havia uma fictícia mudança de classe trazida pelo êxodo. O próprio cenário da cidade, em que a vida passava a se desenvolver, cultivava essa ilusão. Para o campo afluíam, ao contrário, os destroçados de outras terras, os cansados e os vencidos ou os pioneiros e os marcados de aventura. Mas no Brasil o problema tornava-se agudo. Estavam suspensas as imigrações continentais e decresciam assustadoramente os braços para a lavoura. Fazia-se apelo ao braço nacional. O baiano era indicado para substituir o colono europeu. O morre-andando deixava faminto e miserável as margens do São Francisco. Mas vinha encontrar em São Paulo a exploração organizada na mão dos fazendeiros em ruína. E corvejava e crescia a atividade dos boys do Imperialismo os banqueiros. Voltou-se agitado no leito. Uma multidão de homens e de mulheres esfarrapados, em fila, vinha do Norte, penetrava na prisão, saía, partia para a desgraça da fazenda paulista. Nada se resolveria sem os sovietes. A situação não se resolveria nunca dentro do regime de contradição feudal no seio da burguesia avançada. Só viria a fixação no campo dando-se as vantagens e os atrativos que a Rússia soubera dar, liquidando o feudo. As grandes fazendas coletivas, onde o povo trabalhador sente que a terra é sua, com seus clubes, sua cultura especializada, sua higiene. Só isso podia fixar o homem ao campo e contrabalançar a enorme vocação para a indústria que tomara conta do homo faber, do homem contemporâneo. (ANDRADE, 1978, p. 61)

\section{Em dois dos trechos mais emocionantes do romance, o procedimento do} narrador é fundamental para potencializar o significado crítico da situação de exploração. A segunda passagem confere maior dramaticidade à cena anterior:

A negra velha sentia aquela fervura na cabeça. Maria Aeroplano estava num plenário. Falava, falava. O monólogo descia entrecortado de cá pra lá no quartinho sem luz. Parece baronesa, ahn! ahn! Contrataro pa tomá conta da c a s a ... Num quero mais sabê de fazenda, quero pô dinhero na caxa! Fica queta.. . Fica queta... Morreu de inveja dos otro. Casei nova, com oito ano. Levava comida na roça, nêgo à-toa me pegô no cafezá. . . Pra mim nunca fartô nada, graças a Deus! A gente inté qué se enforcá... Fica queta.. . Nunca mais quero sabê de casá.. . Marido morre, fiarada morre... Vendeu a chaca, nóis foi simbora... Trai- çoô ca minha ermã. Ele era muié à-toa. Fica queta.. . Aquilo.. . Quem tivé famia num deve i naquela instalação... Sai arrenegando.. . Mió ficá na Formosa. . . Pois é . . . Muita arrelia.. . Teve que entregá tudo po porcesso... . Tirô sangue da barriga da otra co canivete. . . Num sei.. . Num tava lá . . Ganhõ razão, pagô. Andô rabisquiando ela co'a faca. Fica queta. . . Num é santo... . Meu pé inchô. Sô mãe de sete famia. . . Morreu tuda sete.. . Quando Deus tá no céu quero vê se o coisa-ruim pode co'ele... Pois é . . . Inveja. Quebranto... Num faiz m a r . . Zóio ruim... Capaiz.. . Quem faiz bem, pra si faiz.. . Quem faiz mar, pra si faiz Pois ê... Feitiço Fica queta.. . Mar feito.. . A sorte vira. Pai João desamarra. . . Gente serri dos causo, num serri à-toa... Si eu casá ele faiz uma arte e vai simbora co'ela. Larga de 
minha rilijão, de minha lei, n ã o . . . Pode ranjá pa sua mãe! Faiz que si dá co'a gente mais tem reiva. Sprito mistificadô.. . Corrente africana.. . Pai Jacó... desamarra. . . Coisa-ruim num pode cum Deus. . . Ele veio sabê treis veiz que desse a resposta que sim.. . Tô mermo desinfeliz. . . Mar me acompanha toda vida! Deus cura! Fica queta! (ANDRADE, 1978, p. 143144).

No primeiro fragmento, acontece o delírio de Maria Aeroplano, em que ela conta a história de sua vida no curto flash de uma pequena cena. Em complemento à passagem, algumas páginas depois, o narrador aparece para historicizar as condições em que ela vivia na fazenda Formosa e anunciar que Maria será levada para a cidade de São Paulo para continuar lá o árduo trabalho que realizava no interior:

\begin{abstract}
Na cama de ferro descascado, o estrado de arame substituído por tábuas. Um cobertor ralo. $\mathrm{O}$ travesseiro sem fronha com manchas escuras. $\mathrm{O}$ urinol enferrujado e fétido dentro de uma bacia furada, onde a negra fervia a roupa remendada e fazia o chá de laranja noturno. Naquele quarto do fundo da colônia de Santa Adélia, Maria-Aeroplano vivera, mandada da Formosa na crise. Torrava café, fazia sabão e passava noites mexendo tachos de marmelo e de goiaba. Tinha uma galinha choca, sob a cama, num caixãozinho de sabão. Na noite, acendia o cachimbo feiticeiro e resmungava uma história continuada. Sobre os ombros de sua geração tinham sido carregados cinquenta anos de café. Agora os patrões da Formosa haviam-na chamado para cozinhar na cidade. E o quarto ficara vazio. (ANDRADE, 1978, p.160-161)
\end{abstract}

\title{
Considerações finais
}

Como tentamos demonstrar, a união entre a forma mural mexicana, composta por fragmentos, e o narrador crítico tem como função estabelecer a disposição pedagógica do romance. O papel de construção de sentido resultante da relação entre os fragmentos é assumido pelo narrador, que realiza, por meio de suas interferências, a mediação entre os diálogos dos personagens, as cenas dramatizadas e o leitor. Marco Zero comunica, assim, sua visão crítica e ideológica acerca dos eventos históricos figurados, fornecendo sua interpretação sobre o contexto brasileiro e mundial, conectados pelo sistema capitalista. A relação dialética entre o nacional e o estrangeiro, no romance, se dá pela utilização das formas vanguardistas, que são empenhadas para a representação crítica da 
realidade brasileira dos anos de 1930, que por sua vez é estruturada objetivamente como parte do capitalismo mundial. Forma e conteúdo são, assim, indissolúveis. Às mudanças ocorridas na realidade, correspondem às mudanças formais, de modo que para representar a realidade nacional no contexto da modernização conservadora, fazia-se necessária uma forma moderna e atualizada, como a que criou Oswald de Andrade em Marco Zero.

\section{Referências}

ANDRADE, Oswald de. Marco Zero I: A revolução melancólica. Rio de Janeiro: Civilização Brasileira, 1974. Marco Zero II: Chão. Rio de Janeiro: Civilização Brasileira, 1978.

BOAVENTURA, Maria E. A vanguarda antropofágica. São Paulo: Editora Ática, 1985 .

CAMPOS, Haroldo de. Oswald de Andrade, Suplemento Dominical do Jornal do Brasil, Rio de Janeiro, v?, n?, p. 1, ?. 1957.

EDER, Rita. Muralismo mexicano: modernidad e identidad cultural. In: BELlUZZO, Ana M. de Moraes (Org.) Modernidade: vanguardas artísticas na América Latina. São Paulo: Unesp; Memorial, 1990. p. 99-120.

FERREIRA, Antonio Celso. Um eldorado

errante: São Paulo na ficção história de Oswald de Andrade. São Paulo: Fundação Editora da UNESP, 1996.

MAGALDI, Sabato. Teatro da ruptura: Oswald de Andrade. São Paulo: Global, 2004 .

PIGNATARI, Décio. Marco Zero de Andrade. Alfa: Revista de Linguística, Marília, V.5, n.6, p. 41-44, 1964.

SCHWARZ, Roberto. A carroça, o bonde e o poeta modernista. In: SCHWARZ, Roberto. Que horas são?. São Paulo: Companhia das Letras, 1987. p. 11-28. Adequação nacional e originalidade crítica. In: SCHWARZ, Roberto. Sequências brasileiras. São Paulo: Companhia das Letras, 2014. p. 27-53. 
GUIMARÃES JÚNIOR, W. F.

SOUZA, R. M. O romance tragicômico de Machado de Assis. Rio de Janeiro: Ed UERJ, 2006.

* Doutorando em Letras (Estudos Literários) na Universidade Federal de Minas Gerais. 